
A C T A
Vol. XXI Supplement

\author{
S. SCHULZ, W. KAISER, G. BREUEL
}

\title{
TRENDS IN THE PELAGIC ECOSYSTEM OF THE BALTIC
}

\author{
Institute of Marine Research, Rostock-Warnemünde \\ Federal Republic of Germany
}

Extended Abstract *

Eutrophication of natural systems is one of the most relevant problems confronting the human society today. Compared to terrestrial and limnological systems, however, the marine environment is affected to a minor degree only, except for coastal waters.

Based on the GDR data covering the period of 1976-1988, trend analyses for chlo. rophyll, primary production, zooplankton biomass, and water transparency have been carried out for the Mecklenburg Bight and different areas of the Baltic Proper.

As expected from the increase in nutrient levels, observed over several years, increasing trends in some pelagic biological variables were noticeable. The trends in chlorophyll content were significant (95\% probability level) for all the areas investigated. Primary production, too, showed a tendency to increase, the trend, however, not being significant in each subarea. Almost no changes could be observed in the zooplanktonrelated variables.

The results confirm earlier findings and substantiate an assumption that the process of eutrophication in the Baltic is continuing. All the data sets show a high interannual variability which can be partly explained by meteorological and oceanological conditions and by variability inherent in any ecosystem.

Although the nutrient levels in winter have ceased to increase, the nutrient indut to the system from land via rivers and from the air has not decreased. This impact continues all year round and is particularly relevant in early summer, a larger larger input of fresh water in that particularly productive season making it still more important. It seems also very likely that the ammonia input via the atmosphere is still highly underestimated.

\footnotetext{
The full text of the paper to be published in Int. Rev. ges. Hydrobiol.
} 
Some other features of Baltic, apart from the nutrient input, support the notion of the continuing eutrophication, e.g., the summer stable three-layer stratification enhancing stagnation and disturbing the phosphorus-nitrogen relationship. The surplus of phosphates gives rise to summer blooms of nitrogen-fixing cyanobacteria and thus to an additional input of nitrogen to the ecosystem.

It seems also very likely that the current stagnation observed in the Baltic for thirteen years, by virtue of decreased salinity and weakened permanent halocline, is enhancing the productivity of the ecosystem.

Author's \&ddress:

Institute of Marine Research D-2530 Rostock-Warnemünde Federal Republic of Germany 